\title{
生态保护背景之下衍生出来的生态市政工程技术
}

\author{
李广才 \\ 新疆维泰开发建设(集团)股份有限公司 \\ DOI:10.32629/eep.v2i8.397
}

[摘 要] 在我国社会经济发展水平全面提升背景下,生态市政工程技术也逐渐得到了稳定发展,但是基于当前从事建设和管理工作的人员素质 较低, 缺乏专业性, 因此在实际工作中仍然存在很多不完善的情况和问题,如果不能及时对其进行解决,必然会对我国生态市政工程建设质量带来 负面影响。针对这种情况, 本文就将对生态保护背景下衍生出来的生态市政工程技术问题展开详细研究, 希望对后续城市建设和发展提供有效帮 助与指导作用。

[关键词] 生态保护; 市政工程; 生态技术

随着市政工程项目建设的生态化发展背景逐渐推进, 市政工程施工工 作中的各项工序复杂程度也有了显著提升, 但是目前我国运行的生态市政 工程仍然存在很多问题, 工作人员专业素质不足, 没有认识到相关工作开 展的重要性, 因此在生态市政施工过程中要想切实推进管理工作的开展存 在很多问题和困难。在现代化发展工作全面推进背景下, 生态保护工作的 优势更为显著, 市政工程技术问题的发展也逐渐成为了群众关注的重点问 题。基于此, 本文就将以生态保护作为研究基点, 进一步分析生态市政工程 技术问题, 希望对我国生态保护建设工作的开展提供有效帮助和指导作用。

\section{1 生态市政工程技术在生态保护背景下应用的重要性}

市政工程是我国城市化建设工作中最关键的一项基础设施工作, 在完 成市政工程建设后, 不仅可以有效提升城市整体经济发展水平, 同时还能 为广大群众提供更为显著和优异的生产生活环境。因为在开展市政工程的 过程中要确保和生态系统之间形成物质循环交换, 这也说明城市生活发展 要逐渐进行生态系统的过度, 只有这样才能实现群众物质生活水平的显著 提升 ${ }^{[1]}$ 。与其相关的调查工作中, 市政工程也是生态系统优化后最为直观 的表现内容, 所以相关工作人员也应该在发展过程中加强对当前资源的有 效应用, 只有这样才能在后续工作中形成更为健全和稳定的资源环境。比 如在市政给排水工程项目开展过程中, 应该确保群众生产生活中的各项用 水需求得到充分满足, 在完善电力系统和能源供应系统基础上, 实现水资 源利用效率的稳定提升。此外, 一些市政工程也应该充当区域生态系统的 分解者, 实际上就是在市政工程建设措施中增加相应基础, 保证城市发展 中的相关废气物质得到有效调整, 只有这样才能确保符合生态系统目标的 有效构建 ${ }^{[2]}$ 。但是研究发现, 当前很多工作人员并没有意识到生态保护工 作的重要性, 在这一基础上就需要制定和构建更为完善的工作系统, 确保 工作人员对生态保护问题有着更为全面和精准的认识。

\section{2 目前市政工程领域对生态技术措施应用情况的研究}

生态市政工程技术发展中仍然存在工作人员专业素质不足的问题。目 前大部分生态市政工程建设单位都逐渐认识到了工作人员在工作中的重 要作用, 因此希望通过培训工作和交流实现工作人员综合素质的提升, 只 有这样才能确保生态建设成本得到合理控制。但是在实际研究中可以发现, 目前工作人员的专业素质和生态技术水平仍然比较低下, 不能对复合生态 系统的建设目标进行准确了解, 长期在此种背景下其设计出来的施工图纸 或是工作技术也无法满足群众的发展需求 ${ }^{[3]}$ 。

此外, 工程技术和单位领导者自身管理意识存在明显滞后性问题。由 于我国生态保护背景下的市政工程技术目前仍处于刚刚起步的发展阶段, 所以生态市政工程技术人员在对相关技术和管理模式进行应用的过程中 必然会存在滞后性问题, 由于管理效果始终无法得到稳定提升, 所以技术
发展水平的提升必然会受到严重影响。

\section{3 生态市政工程建设中的主要问题}

3. 1生态市政工程管理意识和技术落后问题严重

在开展市政施工管理工作过程中, 仍然存在明显的理念和技术手段落 后问题, 如果不能将这一问题进行有效解决, 将直接对生态市政工程建设 工作的开展起到负面影响。和先进的西方国家相比, 我国这一技术的起步 时间较晚, 所以在施工技术上往往和西方国家存在较大差距, 在管理工作 中, 需要加强对先进技术理念的学习 ${ }^{[4]}$ 。但是在不断的学习和发展过程中, 我国并没有对实际施工情况进行有效结合, 加之工作人员自身素质水平有 限, 所以在工作中并不能对生态市政工程的管理效果进行最优化体现。

3.2 生态市政工程人员素质水平有限

在开展市政管理和施工建设过程中, 施工人员是最关键的组成环节, 但是当前很多企业为了降低工作成本, 在对施工人员进行选拔的过程中并 不能对工作人员的专业性、综合素质问题进行考虑, 这也造成工作人员在 实际技术落实中并不能对建设工作的整体流程进行准确掌握, 无法对施工 图纸和技术文件中的要求进行准确落实, 这不仅在一定程度上影响和限制 了生态市政工程的建设, 同时也对我国市政建设水平的稳定发展产生了较 为显著的负面影响 ${ }^{[5]}$ 。

\section{4 对生态保护背景下生态市政工程技术进行提升的相关对策}

在上文的研究过程中我们应该认识到, 虽然当前社会发展水平有了显 著提升, 但是社会整体对生态保护问题的关注仍然过于片面, 致使生态市 政工程技术发展也受到了显著影响。为此, 下文就将对相关提升策略进行 详细论述:

4. 1对市政施工管理人员的整体素质进行提升

要想实现对生态市政工程管理水平的提升, 最重要的问题在于提升管 理者的素质。只有确保市政施工管理着自身安全意识和专业意识得到稳定 提升, 才能为后续工程技术的开展提供重要帮助。在市政工程开展前, 应该 切实加强对准备工作的开展, 正确认识到在实际工作中可能出现的问题, 这样工作人员在工作过程中才能有效应对各种技术问题和安全问题, 通过 问题的有效预防, 降低工程完工验收后的返工率。

4.2 对生态市政工程管理监管力度进行提升

在开展生态市政工程的管理环节中, 还应该加强对施工项目管理要素 的科学监管。在监管工作开展过程中, 主要是对工程建设人员、机械设备 运行和技术应用情况进行监督, 确保在实际工作中可以严格按照工程图纸 要求和制度规范进行工作。特别是在对机械设备进行监管的环节中, 更需 要加强对设备的有效监管, 定期进行专业检修和维护, 避免在实际工作中 出现设备安全问题 ${ }^{[6]}$ 。在施工流程管理环节中, 要确保施工流程和技术手 


\title{
城市园林景观植物选配与设计误区
}

\author{
孙士峰
}

同创工程设计有限公司

DOI:10.32629/eep.v2i8.412

[摘 要] 作为城市园林建设的软景观, 园林植物应适应当地条件,科学设计并适合居住。根据现场条件,结合植物材料的特性和环境要求, 可以种 植各种植物。做得好。在遵循生态学的基础上,根据美学的要求, 我们将进行融合创作以实现不同的步骤和时移; 创造比自然更好的美丽风景, 充分发挥其综合功能,服务于城市,服务于公众。

[关键词] 城市园林; 景观设计; 绿化

城市生态园林建设是城市绿化的必由之路。在城市生态园林建设中, 园林植物的选择, 应用和配套至关重要。但是, 在设计和应用中还存在一些 不容忽视的问题, 特别是对绿色植物的选择缺乏科学认识, 从而忽略了城 市园林建设的科学, 艺术, 生态和社会效益。

\section{1 城市园林绿化植物选配的误区}

1. 1 图案化现象

由于日益流行的国际化趋势的影响, 许多城市正在竞相模仿更成功的 花园设计, 从而使各种区域的城市美化成为模型, 例如大规模种植草坪和 雕塑; 灌木种植在大块和大拼写, 大修剪等。

1. 2 大量引进外来植物

在城市美化环境中, 模仿他人并追求时尚, 从而大量引进外国树木和 花卉。每种外来物种的引进都会对当地的生态平衡产生影响。引入和移植 具有不同起源和习性的植物, 很难在它们之间取得平衡。此外, 它们必须与 当地环境和生物学相融合, 以形成新的生态平衡。还是要花很长时间同时, 这些植物在当地的适应性往往很有限, 因此管理成本过高, 浪费了大量的 财力, 物力和人力, 不利于城市生态园林建设。

1. 3草木少现象

段的应用全面满足施工规范, 保证工作的开展实现多方面监督, 只有这样 才能为生态市政工程质量的提升奠定良好基础。

4. 3对生态市政工程建设人员的综合素质进行提升

要想为后续生态市政工程建设的整体质量提供必要保证, 就需要在实 际工作中认识到工作人员的重要作用。这也要求相关建设企业不应该为了 控制生产成本直接降低建设人员招募的标准, 而是应该在人员招募过程中 选取一些素质良好、专业性强的工作人员参与施工工作 ${ }^{[7]}$ 。同时, 还应该 对施工人员的培训工作进行关注, 保证这项工程中的图纸和项目更好的满 足生态建设要求, 这对于施工质量的整体提升也将发挥着不可忽视的关键 性影响。

\section{4 构建健全的生态市政工程管理标准}

在开展生态市政项目工程过程中, 要制定更符合施工标准和施工目标 的制度。目前我国已经对生态市政工程施工建设工作提出了明确的制度要 求, 所以相关企业也应该按照工作标准和要求积极参与工作建设。在确保 建设人员和管理人员严格按照施工企业要求标准开展工作的同时, 更好的 实现工作质量提升, 只有这样才能为生态市政工程建设作用的发挥奠定良 好基础。

\section{5 结束语}

综上所述, 在当前我国城市建设工作稳定开展背景下, 群众对生态市 政工程建设的重视程度也有了显著提升。但是在传统工作理念的影响下,
在美化环境中大规模种植草坪, 虽然绿化面积增加了, 但绿化量没有 增加, 绿化的生态效益不明显。在人口多, 空间少的城市特殊环境中, 大草 坪的布局不仅缺乏空间的尺寸变化, 而且不能满足人们的舒适度要求。大 量开放式草坪的建设将减少人们的活动数量, 并使城市风光变得单一。就 像画一幅只有背景而没有内容的图片一样。这不是一项好工作。大量的开 放式草坪被修建, 以增加园林绿化管理的成本。同一地区的草坪管理成本 是灌木和灌木的 $4-5$ 倍, 生态效益仅为同一地区的 $1 / 4$ 。

\section{2 城市园林植物的选配研究}

2.1 注意植物的生物学特性

2.1. 1 取决于气候和土壤条件

树木的选择应适应当地条件并适合树木。在各种园林树木的生长发育 过程中, 对环境因素 (例如光, 湿度, 温度和土壤) 的要求不同。为了满足园 林树木的这些生态要求, 必须适合于树木。二是做好合理的种植结构。根 据当地土壤环境条件, 选择适合生产和种植的树种。

2.1.2根据所需的光强度安排栽培区域

根据树种对日光的需求强度, 合理安排生产耕地和绿化利用场所。森 林边缘或空旷地区的大多数原生物种都是高光物种。而灌木的树种可以用

之前的生态保护工作并没有得到有效发展。所以在今后城市化水平全面推 进的同时, 我们更需要加强对生态市政工程建设工作的关注。除了应该对 上述监督管理制度进行落实之外, 还应该加强对相关监督机制的构建, 保 证工作人员在工作建设环节中实现工作准确性和有效性的全面提升, 只有 这样才能为我国市政工程建设质量的提升提供更显著的积极影响。

[参考文献]

[1]高翔.市政规划中循环经济理念的应用分析[J].建筑工程技术与设 计,2018,14(8):2869.

[2]刘泽森. 基于生态保护的公路线形设计 [J]. 工程技术研 究,2018,23(13):147-148.

[3]范益群,许海勇.城市地下空间开发利用中的生态保护 [J].解放军理 工大学学报(自然科学版),2014,57(3):209-213.

[4] 陈海江。绿色环保下市政工程施工技术分析 [J]. 低碳地 产,2016,27(12):395.

[5]陈海江。绿色环保下市政工程施工技术分析 [J].中国房地产 业,2016,17(11):197.

[6]曹富珊.浅谈市政工程的绿化项目管理[J].城市建设理论研究(电子 版),2012,35(1):53.

[7]吕永鹏, 谭学军,邹伟国.新安江流域综合规划: 兼谈流域防洪与生态 保护[J].城市道桥与防洪,2012,28(8):26-28. 